\title{
Method of Modeling Linguistic Personality Types as Way of Studying National Picture of World
}

\author{
Olga Dmitrieva ${ }^{1}$, and Dmitry Gulinov ${ }^{2 .}$ \\ ${ }^{1}$,Department of Russian as a Foreign Language, Volgograd State Socio-Pedagogical University, 27 Lenin Av., Volgograd, \\ 400066, Russia \\ 2., Department of Roman Philology, Volgograd State Socio-Pedagogical University, 27 Lenin Av., Volgograd, 400066, Russia
}

\begin{abstract}
The article proposes the solution of the problem of cognitive modeling in the form of a linguistic personality type - a typed language personality whose behavior and whose value orientations significantly influence the linguistic culture as a whole and which are indicators of the ethnic and social identity of the society. A technique for modeling linguistic personality types with illustrative material is proposed. The study of linguistic personality types promotes a better understanding of the features of linguistic consciousness and communicative behavior of representatives of different societies, and, as a result, it allows optimizing the process of intercultural communication.
\end{abstract}

\section{Relevance of the study}

The cognitive direction in linguistics began to be actively formed in the 90 s of the twentieth century when, due to the global integration processes in the society, the traditional problem of understanding of cultures became recognized as a complex interdisciplinary problem that has its socio-psychological, socio-cultural, scientific aspects. One of the founders of linguistic cognition, N. Chomsky [1], called for the study of the natural properties of a language, the connection of linguistic units with the perception of the world, and noted more than once that scientists have for too long focused on the external manifestations of the language, its exteriorized forms; now we have to deal with its properties inside the brain - the internalized structures of the language. At the same time, the interest of scientists in the personal aspect of language increased. This aspect has been developed over the past decades within the framework of linguistic personality studies, an independent direction of linguistics, distinguished in the framework of anthropocentric language studies and based on the achievements of linguistics, literary criticism, cultural studies, psychology, sociology, the object of whose attention is the subject and their linguistic manifestations. As we can see, the trend towards interdisciplinary research allows scientists to develop new approaches to the object of study [2].The formation of linguistic personality studies anticipated linguistic studies of the anthropocentric orientation, namely the works of Yu. N. Karaulov [3], Yu. D. Apresyan [4] and others on the theoretical and methodological grounds for the studies of linguistic personalities. The theory of linguistic personality types arose as a result of the active interest shown by linguists to the study of linguocultural concepts.

The purpose of this study is to demonstrate the methodology for modeling linguistic culture types.

The work is based on the following hypothesis: linguistic personality types, representing concepts containing a linguistic personality, represent the national specificity of the world picture, are characterized by certain conceptual, perceptual, value characteristics, communicative characteristics, reflected in linguoculture.

Linguistic personality type is a generalized type of personality, distinguished by socially significant parameters within a certain socio-ethnic society, showing certain recurrent characteristics and recognizable by the bearers of a particular ethno- or socioculture according to specific characteristics of verbal and non-verbal behavior and deducible value orientation. Linguistic personality types can have a significant impact on the behavior of representatives of the relevant culture. A distinctive feature of the term "linguistic personality type" is that it emphasizes the cultural and diagnostic significance of the typed person for understanding culture and studying this person from the standpoint of linguistics [5].

The importance of assessing this or that type of personality as a socially significant phenomenon, in our opinion, was well noted by the well-known English thinker, writer and journalist G. K. Chesterton, who was against the exact portraying of a person, since it reveals only minor details relating to the subject: "What a man's name was, what his income was, what he married, where he lived, these are not sanctities; they are irrelevancies" [6]. Chesterton believed that the description of the

* Corresponding author: dmoa@yandex.ru 
personality of the subject should reveal the most important for society data in the value respect of its side. This idea formed the basis of his book "Varied Types", in which they described the personalities of King Charles II, Queen Victoria, Charlotte Bronte, Byron and other outstanding figures of the British culture from the standpoint of the basic values of the British society. Just one special feature, noticed and singled out by Chesterton, sometimes contributes to the formation of a more complete image of personality than a lot of objective "dry" facts. For Chesterton, a subjective approach to describing a person is important, the emotions that this personality causes in most members of society are important - "the only existing thing that is true, emotion, the irreducible minimum, the indestructible germ" [Ibid]. This approach to the description of the subject is consonant with the modern approach to the description of linguistic personality types, in particular, their value component.

According to the theory of linguistic culture types, it is advisable to consider the main characteristics of behavior (including speech) of a linguistic personality type through the prism of the linguistic consciousness of the representatives of the society, while emphasizing the value characteristics of the type, placing the attitude of the representatives of the society on the type of personality under investigation. The study of the linguistic personality type is one of the approaches to the study of the linguistic personality, the peculiarity of which is the establishment of the value significance of this type of personality in the culture of society. A comprehensive study of the type is carried out through the study of the collective consciousness (collective linguistic personality) of the bearers of a particular linguoculture. At the same time, when modeling, some types of speech characteristics may be irrelevant. Description of the speech characteristics of the type is just one of many aspects characterizing the linguistic culture type, the multidimensional phenomenon in linguoculture.

\section{The method of modeling of linguistic personality types (LPT)}

Modeling of a linguistic personality type is based on the specific structure of the concept and the cultural potential inherent in it. The algorithm for describing the linguistic culture type presupposes the selection of the image-perceptive, conceptual, value aspects, and also the compilation of a sociocultural reference.

\section{The first stage of modeling of a linguistic personality type}

The first stage consists in describing the conceptual content of the LPT under consideration on the basis of the analysis of its most important features. The language material for this stage of the study is data from lexicographic sources (explanatory, synonymous, encyclopedic, terminological, special dictionaries).
Conceptual characteristics consist in revealing its essential semantic attributes contained in vocabulary definitions, exploring a synonymic series, establishing additional characteristics. At this stage of the study, a set of lexical units that make up the nominative field of the linguistic culture type is identified, thus constructing a lexico-semantic field of the type based on the linguistic units of the intra- and extra-zones, namely, the incoming associations of concepts. Here is an example: "American gangster": mob, mobster, boss, Don, criminal, racketeer, thug, bully, goon, homeboy, hood, mug, punk, roughneck, rowdy, ruffian, thug, tough, toughie, etc. When forming units of intrazones (mostly lexemes and word combinations with a small number of idioms), scientists used such word-formation methods as composing (gangsterism, gangsterdom, gangstertum, ganger), metonymic (cutthroat, scoundrel, villain; assassin, bandit, bravo, brigand, crook, desperado, felon, gunman, highwayman, lawbreaker, mafioso, outlaw, perpetrator, pickpocket, robber, swindler, thief) and metaphorical (New world, referring to America as the New World) value transfer.

It has been established that lexical agents verbalizing the type's extrazone are formed by conversion (to gang, to gang-bang), affixation (gangsta - modern colloquial version, gansterish), compositional (gangland, gangbanger, gangbuster, gang rape), abbreviations (in modern American colloquial speech abbreviation $G$ is often used in the meaning of the word gangster) and idioms (like gangbuster, to gang up with / on / against) [7].

Based on the interpretive analysis of the most common dictionary definitions, the basic dominants that constitute the content of the studied type are distinguished.

Let us demonstrate an example of such description: «юродивый» (holy fool): 1) a man, 2) a Christian, 3) an ascetic, 4) a prophet, 5) reprove injustice, 6) seem insane, 7) a holy ascetic; "Butler": 1) person; 2) male servant; 3) principal servant of the household; 4) supervising employees; 5) employee; 6) performing domestic services; 7) receiving fees; 8) running winecellar. Thus, the butler is a man (male), an elder servant hired by the owner of the house to do housework, to guide the staff for a certain reward; one of the main responsibilities of the butler is the management of the wine cellar [8]; "English Vicar", which make up its contents: 1) the priest; 2) the Anglican Church; 3) formally appointed head of the parish; 4) receiving a salary; 5) having a set of job responsibilities; 6) who has the authority to manage the parish; 7) having a residence, a parish priest's house [9]. As you can see, the scope of the description of the conceptual component of the linguistic personality type can vary significantly. This, as can be seen, it is directly related to the socio-cultural status of the person / persons underlying the described linguistic personality type.

\section{The second stage of modeling of a linguistic personality type}


The second stage is devoted to the definition of associative and figurative-perceptive features of the type in question in the individual language consciousness of native speakers. They are distinguished on the basis of interpretation of fiction texts, materials from encyclopedias, Internet sites, documentary and feature films, and interviews with respondents. This technique was tested by many researchers, e.g. the example of concept modeling [10, 11].

For this purpose, it is proposed to use a number of experimental methods. At the same time, the number of respondents cannot be less than 1000 people of different sex, age, status, which is due to the need to minimize subjectivism in the responses. Experiments are carried out both in group and in individual form. The participants of the experiment using the method of free definitions are invited to the task: "Please write how you understand the meaning of the word" ... ". In quotation marks, a noun that acts as a nomination of a type is prescribed. Participants of experiments (when the Bendix method is used) are asked to compare a word that refers to a type with similar words to it, for example, предприниматель and бизнесмен, делеи, the most frequent synonyms for the word entrepreneur as in dictionary definitions (businessman) and in the minds of native speakers (the money-bag is a wealthy entrepreneur). Participants of the experiments were offered the task: "Finish the phrase: "OH предприниматель, а не бизнесмен, потому что...», «Он предприниматель, а не делеи, потому что ...», «Он предприниматель, а не толстосум, потому что...» (He is an entrepreneur, not a businessman, because .... "He is an entrepreneur, not a money-bearer, because ... "). It is also advisable to use a free associative experiment, during which respondents list the association words for the stimulus-the name of the type. The received language material allows one to present the image-perceptive characteristic of the linguistic personality type under analysis.

Let us illustrate by an example: The professional linguistic personality type "American lawyer" is characterized by the following basic figurative and perceptual characteristics: it is usually a middle-aged man with an astute gaze and a charming smile, in an expensive suit, usually educated in a private school and a prestigious university, masterfully mastering the techniques of oratory, advising clients, speaking in court, leading tense negotiations with representatives of the prosecution, plaintiffs and defendants, carefully formulating law texts, living in a prestigious area in an expensive mansion or luxury apartment, having an expensive car [12].

Here is another example of the description of figurative features on the example of LPT "British Colonial Employee" from a study by V. V. Derevyanskaya:

"The most important figurative signs of the historical linguistic personality type "British colonial employee" are the following:

1) a tanned man with a mustache, in a uniform, or in a summer suit and cork helmet, or in church vestments;
2) the main activities of the colonial administrators were to ensure the political and economic interests of the British Empire, the small clerks were responsible for keeping the records, the officers directed operations to seize new territories and were to maintain order in the colony, the missionaries led the Christianization of the local population and provided initial training; employees of trade companies provided trade and economic links between the colony and England, employees of construction and industrial companies developed the infrastructure of the colony, developed natural resources, doctors provided medical assistance to the local population;

3 ) the place of leisure for colonial employees was the English club, where they played cards, billiards, polo and tennis, conducted conversations, read English magazines and newspapers of a month ago, ate traditional English food with the addition of some local national dishes;

4) the speech of the colonial employees included the names of local realities and varied greatly depending on the social origin; speech of clerks, engineers and forestry agents is distinguished by an abundance of abusive, slang words [13]. Specifics of communicative behavior of a linguistic personality type should be considered as a verbal level (rules, traditions of speech communication, etiquette formulas, observance of time limits, intervals of communication, etc.), and on the nonverbal (a set of rules and traditions that regulate situational conditions of communication, facial expressions and gestures, the organization of space in communication). Both types of behavior are inextricably linked. In addition, communicative behavior is associated with communicative consciousness, which refers to the totality of the mechanisms of the individual's consciousness, which ensures their communicative activity [14].

\begin{tabular}{|c|c|c|}
\hline $\begin{array}{l}\text { Scheme by Olga } \\
\text { A.Dmitrieva }\end{array}$ & $\begin{array}{l}\text { Results of } \\
\text { Experiment } 1\end{array}$ & $\begin{array}{l}\text { Results of } \\
\text { Experiment } 2\end{array}$ \\
\hline $\begin{array}{l}\text { indication of } \\
\text { typical } \\
\text { appearance, } \\
\text { clothes, } \\
\text { attributes }\end{array}$ & $\begin{array}{l}\text { alcohol or drug } \\
\text { addiction }\end{array}$ & $\begin{array}{l}\text { bright makeup } \\
\text { and good } \\
\text { hairstyle; } \\
\text { slenderness; } \\
\text { decorations, } \\
\text { accessories }\end{array}$ \\
\hline place of living & $\begin{array}{l}\text { belonging to a } \\
\text { particular } \\
\text { society; } \\
\text { a certain period } \\
\text { of time - the } \\
\text { 19th century } \\
\text { (desired or real); } \\
\text { consciously } \\
\text { carried out } \\
\text { changes in the } \\
\text { life of the } \\
\text { heroine }\end{array}$ & $\begin{array}{l}\text { creative } \\
\text { environment, } \\
\text { the sphere of } \\
\text { art }\end{array}$ \\
\hline $\begin{array}{l}\text { description of } \\
\text { speech } \\
\text { characteristics, }\end{array}$ & $\begin{array}{l}\text { theatricality, } \\
\text { playfulness of } \\
\text { behavior; }\end{array}$ & $\begin{array}{l}\text { arrogance, } \\
\text { mannerisms; } \\
\text { mystery; }\end{array}$ \\
\hline
\end{tabular}




\begin{tabular}{|l|l|l|}
\hline $\begin{array}{l}\text { manners of } \\
\text { behavior, } \\
\text { speech }\end{array}$ & $\begin{array}{l}\text { some } \\
\text { promiscuity; } \\
\text { arrogance }\end{array}$ & $\begin{array}{l}\text { intelligence, } \\
\text { good manners }\end{array}$ \\
\hline $\begin{array}{l}\text { ritual actions, } \\
\text { scope of activity }\end{array}$ & $\begin{array}{l}\text { fascination with } \\
\text { mythology, } \\
\text { mystification, } \\
\text { mystery }\end{array}$ & $\begin{array}{l}\text { the sphere of } \\
\text { art }\end{array}$ \\
\hline $\begin{array}{l}\text { leisure, social } \\
\text { circle }\end{array}$ & $\begin{array}{l}\text { affiliation to a } \\
\text { certain social } \\
\text { layer }\end{array}$ & $\begin{array}{l}\text { exhibitions, } \\
\text { shows; } \\
\text { artists, poets, } \\
\text { musicians }\end{array}$ \\
\hline $\begin{array}{l}\text { financial } \\
\text { situation }\end{array}$ & $\begin{array}{l}\text { good financial } \\
\text { position }\end{array}$ \\
\hline origin & $\begin{array}{l}\text { orphan or } \\
\text { parents }\end{array}$ & $\begin{array}{l}\text { more frequently } \\
- \text { young age }\end{array}$ \\
\hline Age & \multicolumn{2}{|c|}{} \\
\hline
\end{tabular}

These descriptions differ only formally: a description in the form of text and a description with the isolation of individual associative attributes. However, the materials obtained by experiment must be supplemented with data from different genre texts, cinematography and Internet sources containing a context with a description of the modeled type. As an illustration, let us give an example of a comparative analysis conducted by E.M. Dubrovskaya, during which she found inconsistencies in the characteristics of the "Bohemian Man" type, established according to the respondents' survey and the analysis of text materials [15].

\section{The third stage of modeling of a linguistic personality type}

Stage III includes the identification of value and evaluation characteristics of this type in the selfpresentation and presentation of others.

The value aspect is the positioning of the type in the value system of linguoculture, which has a dual characteristic: individual and collective. At the same time, there is a tendency to lose personal appreciation, due to the attraction to figurative, symbolic perception in the public consciousness. The linguistic personality type itself can be presented simultaneously as a set and hierarchy of values in the system of value orientations, and have an appraisal characteristic in society ("hussar" - brave, bold, "computer man" - poorly oriented in the real world, "Muscovite" - referring to the higher world, beau monde, "Gascon" - courageous, brave). The value aspect is fundamentally significant in the structure of the concept in general, and linguistic personality type in particular, it is this component that is culturally significant. There are four main types of values fixed in the collective consciousness of an ethnos: moral, utilitarian, supermoral and subutilitarian values. The ratio of these values creates a specific value picture of society. Subutilitarian values reflect the person's vital needs for food, pleasure, warmth, procreation, etc. and are universal in nature. Utilitarian values express the priorities of the material (well-being, comfort, health, etc.) and the ideal order (symbolic capital) for the individual. Moral values put the interests of the society, and not the individual on the first place, and are expressed in a system of detailed standards of society aimed at protecting the weak, respect for elders, readiness for self-restraint. Supermoral values express higher symbolic differences of society as a whole, are not subject to rational explanation and should be taken for granted. Supermoral and subutilitarian values are perceived as a priori guidelines of behavior, they do not need proof and are not expressed in the norms of behavior fixed in everyday communicative behavior. Moral and utilitarian values need to be explained and consolidated in the behavior of people during the upbringing of children and on the basis of traditional mechanisms of social adaptation.

It is known that the value priorities of a society during its history undergo changes, whereas ethnic values are characterized by constancy, i.e. do not have a content and are formal characteristics.

From a linguistic point of view it is of interest to analyze linguistic personality type casting isolate national specificity linguocultures taken for comparison, to determine value characteristics and ethnic constants recorded in the language. If ethnic constants and the value system are correlated as a mode of action and the purpose of the action, then the study of the linguistic personality type should follow these two directions. We can imagine the specifics of the communicative behavior of different linguistic cultures in the same set conditions. We will see that to achieve one common goal, the types behave differently.

The estimated characteristics of the analyzed type are established on the basis of the analysis of diagnostic utterances, namely the material of a questionnaire, the analysis of dictionaries, manuals, materials of the media, cinema, art, literature, the Internet, that is, all sources bearing information about a certain linguistic personality type. When describing the linguistic culture type, the facet estimation is used, i.e. the evaluation grid includes several directions: the evaluation of the type of self (selfidentification), the self similar, surrounding. We consider the evaluation of the type of the contemporaries around him and his assessment from the current positions. This system shows a linguistic culture from several positions. First, we can trace the transformation of the type into image, role, etc. Secondly, the evaluation of communicative behavior leads us to the scale of value dominants of this type. One of the important aspects of the value characteristic of the type is its self-assessment, which is the basis of self-identification, reflected in the language in expressions such as "we ..." - "we, the bourgeois ...", "for us" - "for us, the Cossacks ...", "us ... "-" We, the hussars ...". Caste, hidden behind the metaphor "we", is expressed in varying degrees of evaluation of representatives of other groups, from positive to negative. So, self-identification is relevant, type-forming sign of linguistic personality type, which determines the normality of communicative behavior within the limits of the priority scale. For a linguistic 
personality type, identification is a relevant feature. The higher the society values the status of a certain type, the stronger the degree of identification with it. Accordingly, the more often representatives of this status seek to distinguish themselves from others through social symbols. The loss of their status is assessed negatively, and vice versa, every effort is made to raise their status.

There is a certain dynamics of representation about the historical type from the side of his contemporaries and representatives of our time. Contemporaries pay attention to all the characteristics of the characters, while for the representatives of our time the value characteristics of the type come to the fore. The method of describing the type through the eyes of his contemporaries includes, first of all, the analysis of texts of fiction and the epistolary heritage, and to understand the specifics of comprehending the type in the minds of representatives of our time, sociological methods of research are relevant (questioning and interviewing informants).

\section{Conclusion}

The theory of linguistic personality types is one of the actively developing areas of linguoculturology, linguistic personality studies and linguoaxiology. The essence of the theory of linguistic personality types is to isolate and analyze concepts containing a linguistic personality built into the linguistic picture of the world and functioning in it, interacting with other lexical units. A linguistic culture type is understood as a "typed person, representative of a certain ethno-social group, recognizable by specific characteristics of verbal and non-verbal behavior and deducible value orientation." In the series of linguistic personality types - recognizable generalized types of personalities - different images of people are distinguished: class (merchant), professional (lawyer), historical (Decembrist), local (Muscovite), socio-psychological (eccentric). Types can be ethnomarked (Chinese healer, Russian intellectual, British aristocrat), or socio-marked (boss, punks, movie stars). Each type has appraisal characteristics, often balanced and representing the addition of valuation vectors (for example, the intellectuals are assessed differently by representatives of the government, the people and the intelligentsia themselves). Linguistic personality types reflect the values established in the ethnos and at the same time serve as a source of the formation of new values in the society. In the research plan, the linguistic personality type is treated as a specific kind of concept, the content of which is a typified linguistic personality.

Linguistic personality types are created on the basis of prototypical images of real historical figures or fictional characters of works of fiction and cinema.

A linguistic personality type, being a version of the concept, includes conceptual, figurative and value components. To study the conceptual aspect, the analysis of vocabulary and other definitions is used, with the help of which constitutive signs of the concept are established. However, the dictionaries contain valuable information for the analysis of the value component of the type [16]. The study of the linguistic culture type also presupposes the construction of the semantic field of the concept of the typed person on the basis of incoming and outgoing associations that make up its intra- and extra-zones and form its nominative density and nominative diffusion, respectively. This field consists of descriptive and evaluative lexemes and wordcombinations and serves as a basis for the allocation of value and associative-shaped dominants.

Interpretative analysis of texts of fiction, cinematographs and questionnaires provides an idea of the figurative aspect of the type and its value characteristics that are actualized in the language in the form of linguistic units appealing to the type.

Thus, the linguistic personality type is the totality of the ethnomarked units in all the structural components of the type. There is no linguistic person in general, it is always national, always belongs to a certain linguistic cultural community. The linguistic personality has a culturally conditioned mentality, a picture of the world and a system of values, because through the language a person gets an idea of the world and the society of which he has become a member, about his culture. It always adheres to certain behavioral and communicative norms, accordingly, when modeling a linguistic culture type, the national picture of the world is reconstructed in a multidimensional perspective: concepts (value dominant), rituals, customs, social stratification, precedent phenomena, stereotypes.

\section{References}

1. N. Chomsky, Rules and representations (N. Y., 1980)

2. S.V. Ivanova, A.S. Borisova, Russian Journal of Linguistics 22 (1), 215-222 (2018)

3. Yu.N. Karaulov, Russian language and language (LKI / URSS, Moscow, 2007) (in Russian)

4. Yu.D. Apresyan, Questions of Linguistics 1, 37-65 (1995)

5. V.I. Karasik, O. A. Dmitrieva, Linguistic personality type: the definition of the concept, Axiological linguistics: linguistic personality types 5-25 (Paradigma, Volgograd, 2005)

6. G.K. Chesterton, Varied Types, Dodd Mead and Company (1903) URL: http://www.questia.com/library/book/varied-typesby-g-k-chesterton.jsp (date of access: 10.02.2018).

7. Yu.V. Kakicheva, V.N. Zatyamina, Linguistic personality type "American gangster", Axiological linguistics: linguistic personality types, 42-55 (Paradigma, Volgograd, 2010)

8. T.V. Bondarenko, Linguistic personality type "English butler", Axiological linguistics: linguistic personality types, 74-90 (Paradigma, Volgograd, 2010)

9. L.N. Brovikova, Linguistic personality type "English Vicar" Axiological linguistics: linguistic 
personality types, 90-99 (Paradigma, Volgograd, 2010)

10. S.V. Voloshina, M. A. Tolstova, Tomsk State University Journal 425, 12-18 (2017)

11. S.K. Sevastyanova, Tomsk State University Journal 425, 32-49 (2017)

12. E.V. Gulyaeva, Linguistic personality type "American lawyer", 177 dis ... cand. Philol. Sciences (Volgograd, 2009)

13. V.V. Derevyanskaya, Linguistic and cultural type "colonial employee", 216, dis. ... cand. Philol. Sciences (Volgograd, 2008)

14. N.F. Alefirenko, M.B. Nurtazina, Russian Journal of Linguistics, 21 (4), 706-728 (2017)

15. E.M. Dubrovskaya Linguistic personality "man of bohemia": dynamic aspect: the author's abstract. dis. ... cand.. Philol. Sciences, 24 (Omsk, 2017)

16. L.I. Bogdanova, Russian Journal of Linguistics 21 (4), 729-748 (2017) 